\title{
ISOTERMAS DE ADSORÇÃO DO CORANTE AZUL BRILHANTE POR HIDROGÉIS LIOFILIZADOS A BASE DE QUITOSANA
}

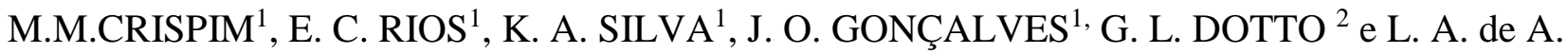 \\ PINTO $^{1}$ \\ ${ }^{1}$ Universidade Federal do Rio Grande, Escola de Química e Alimentos \\ ${ }^{2}$ Universidade Federal de Santa Maria, Departamento de Engenharia Química \\ E-mail para contato: marsellee.martins@ gmail.com
}

\begin{abstract}
RESUMO - O processo de adsorção vem ganhando destaque como alternativa para a remoção de corantes de efluentes. A quitosana, um biopolimero proveniente de fontes renováveis, biodegradáveis e biocompatíveis, vem ganhando notoriedade por sua eficiência na remoção dos corantes alimentícios em efluentes industriais. Os hidrogéis são estruturas de redes poliméricas formadas através de ligações cruzadas, sendo capazes de absorver água e permanecer insolúvel. Desta forma, este trabalho tem como objetivo obter e caracterizar diferentes hidrogéis à base de quitosana, e verificar o comportamento de equilíbrio nas diferentes condições da adsorção do corante alimentício azul brilhante. A caracterização do hidrogel foi feita através da análise do grau de intumescimento, força do gel e MEV. Os experimentos foram realizados com hidrogel liofilizado com e sem a adição de carvão ativado. As isotermas de adsorção foram realizadas variando a temperatura $\left(25,35\right.$ e $\left.45^{\circ} \mathrm{C}\right)$ e a concentração de corante $\left(50,100,200,300,400 \mathrm{mg} \mathrm{L}^{-1}\right)$. Os dados experimentais foram ajustados ao modelo de Lamgmuir $\left(\mathrm{R}^{2}>0,98\right.$ e EMR $\left.<5 \%\right)$. As máximas capacidades máximas de adsorção foram à temperatura de $25^{\circ} \mathrm{C}$ com os valores de 1306 e $1428 \mathrm{mg} \mathrm{g}^{-1}$ para os hidrogéis sem e com carvão, respectivamente.
\end{abstract}

\section{INTRODUÇÃO}

Os corantes artificiais são muito utilizados pelas indústrias alimentícias para conferir, intensificar cor a determinados produtos, visando sua maior aceitabilidade pelo consumidor. Esses aditivos alimentares quando lançados no meio hídrico podem apresentar caráter potencialmente tóxico e cancerígeno, sendo capaz de interferir nos processos fotossintéticos no meio ambiente devido à ações adversas que essas substâncias podem causar (Koprivanac e Kusic et al., 2008; Mittal et al., 2007).

A adsorção é um métodos mais utilizados para a remoção de corantes alimentícios, devido a seu baixo custo inicial, facilidade de operação e eficiência em relação aos métodos convencionais (oxidação, coagulação/floculação, coagulação eletroquímica, tratamento biológico, entre outros), que são de alto custo ou tecnicamente complicados (Demirbas et al.,2009). Um adsorvente promissor para a remoção de corantes em soluções aquosas é a quitosana (Crini e Badot et al., 2008). Este biopolímero apresenta versatilidade, devido as 
possibilidade de modificações químicas estruturais e interações com diferentes compostos. No entanto, quando a quitosana é utilizada na forma de pó, torna-se difícil a separação das fases após a operação de adsorção (Wan Ngah et al., 2011). Desta forma, a preparação de hidrogéis à base de quitosana pode ser uma alternativa para facilitar a separação de fases após a adsorção, inferindo diferentes propriedades no adsorvente.

O objetivo desta pesquisa foi obter e caracterizar hidrogéis de quitosana liofilizados com e sem adição de carvão ativado. A fim de verificar o comportamento destes adsorventes nas isotermas de equilíbrio na adsorção do corante azul brilhante em sistema aquoso.

\section{MATERIAL E MÉTODOS}

\subsection{Elaboração do hidrogel de quitosana liofilizado}

O hidrogel de quitosana reticulado com glutaraldeído foi preparado a partir da dissolução de quitosana $(5,0 \%(\mathrm{~m} / \mathrm{v}))$ em ácido acético $1 \%(\mathrm{v} / \mathrm{v})$. Após, foi adicionado de glutaraldeído com concentração 3,0\% (v/v) para formação do gel (Shen et al., 2011). O carvão ativado $(10 \% \mathrm{~m} / \mathrm{m})$ foi adicionado ao hidrogel no passo da dissolução. O hidrogel foi submetido à secagem a frio em um liofilizador (Liobras, L108, Brasil) por $48 \mathrm{~h}$, utilizando-se vácuo de $44 \mathrm{mmHg}$ e temperatura de $-54^{\circ} \mathrm{C}$.

\subsection{Caracterização do hidrogel de quitosana liofilizado}

Força do gel e grau de intumescimento: A força do gel foi determinada de acordo com a metodologia descrita por Zhou e Regenstein (2007), usando um textuômetro (Stable Micro Systems, RT-XT plus, Reino Unido) com uma sonda de Teflon de 12,5 mm de diâmetro e velocidade $1 \mathrm{~mm} \mathrm{~s}^{-1}$ a qual foi inserida $4 \mathrm{~mm}$ nas amostras, visando determinar a força máxima. A fim de estudar o grau de intumescimento, foram pesadas $100 \mathrm{mg}$ de hidrogel liofilizado e estes foram submergidos em água destilada e a $25^{\circ} \mathrm{C}$ durante $4 \mathrm{~h}$. $\mathrm{O}$ excesso de água superficial foi removido das amostras inchadas. $\mathrm{O}$ grau de intumescimento (GI) foi determinado de acordo com a Equação 1.

$$
\mathrm{GI}=\frac{\left(\mathrm{M}_{\mathrm{t}}-\mathrm{M}_{0}\right) \times}{\mathrm{M}_{0}} 100
$$

Microscopia de eletrônica de varredura (MEV): As avaliações morfológicas dos hidrogéis de quitosana foram realizadas a partir da análise de microscopia eletrônica de varredura (MEV) utilizando microscópio eletrônico (Jeol, JSM 6060, Japão).

\subsection{Isoterma de adorção}

As isotermas de adsorção foram obtidas na faixa de 25 até $45^{\circ} \mathrm{C}$ com diferentes concentrações de soluções do corante $\left(50,100,200,300,400 \mathrm{mg} \mathrm{L}^{-1}\right)$. O pH da solução foi ajustado a pH=3 com auxílio do tampão fosfato dissódico-ácido cítrico 0,1 M L-1 (pHmetro Marte, modelo MB10, Brasil). Após foi adicionado o hidrogel de quitosana liofilizado (250 $\mathrm{mg}$ em base seca), os frascos foram agitados à $100 \mathrm{rpm}$ utilizando um agitador termostatizado (Fanem315 SE, Brasil) por $24 \mathrm{~h}$. Os experimentos foram realizados testando o hidrogel 
liofilizado com carvão e sem carvão. Após, a capacidade de adsorção no equilíbrio de cada corante $\left(\mathrm{q}_{\mathrm{e}}\right)$ foi determinada pela Equação 2:

$$
\mathrm{q}_{\mathrm{e}}=\frac{\left(\mathrm{C}_{0}-\mathrm{C}_{\mathrm{e}}\right)}{\mathrm{m}} \mathrm{V}
$$

Para estabelecer a correlação mais apropriada para as curvas de equilíbrio em todas as temperaturas para cada corante, foi utilizado o modelo de Langmuir. Este modelo assume que adsorção ocorre em sítios específicos e homogêneos do adsorvente, é o modelo mais comumente utilizado para processos de adsorção na monocamada (Guibal, 2004), e está representado na Equação 3.

$$
\mathrm{q}_{\mathrm{e}}=\frac{\mathrm{q}_{\mathrm{m}} \mathrm{K}_{\mathrm{L}} \mathrm{C}_{\mathrm{e}}}{\left(1+\mathrm{K}_{\mathrm{L}} \mathrm{C}_{\mathrm{e}}\right)}
$$

\section{RESULTADOS E DISCUSSÃO}

\subsection{Caracterização do hidrogel de quitosana liofilizado}

O grau de intumescimento (GI) foi dependente do tempo, praticamente estabilizou $120 \mathrm{~s}$ apresentando valores de GI de $113 \pm 2 \%$ e $135 \pm 5 \%$ para os hidrogéis sem e com carvão, respectivamente. Os adsorventes apresentaram uma força do gel ao redor de $730 \pm 5 \mathrm{~g}$ para ambos os hidrogéis.

As características texturais dos hidrogéis liofilizados foram observadas através da análise de microscopia eletrônica de varredura (MEV) apresentadas na Figura 2.

Figura 1- Imagens de MEV dos hidrogéis à base de quitosana: (a) hidrogel liofilizado (b) hidrogel liofilizado com carvão.
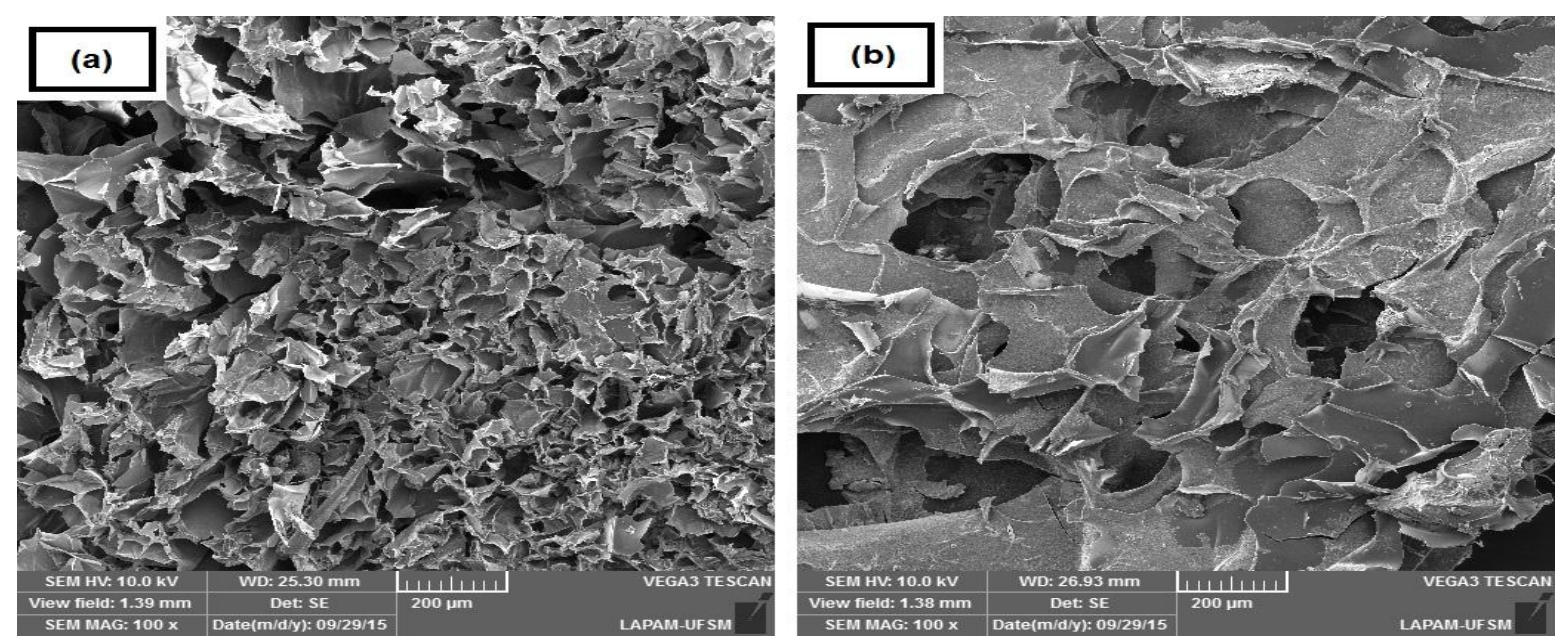

As imagens de MEV apresentam a morfologia dos hidrógeis liofilizados sem e com a 
presença de carvão ativado. A Figura 1 (a) o hidrogel apresentou uma superfície mais fibrosa e com a presença de poros. No entanto, na Figura 1 (b) o adsorvente apresentou uma superfície mais lisa com uma quantidade menor de poros, isto pode ter ocorrido devido à inserção de carvão ativado nos espaços vazios do hidrogel.

\subsection{Isotermas de adsorção}

A Figura 2 apresenta as isotermas de adsorção do corante azul indigotina por hidrogéis liofilizados de quitosana.

Figura 2 - Isoterma de adsorção do corante azul indigotina por: (a) hidrogel liofilizado (b) hidrogel liofilizado com carvão.
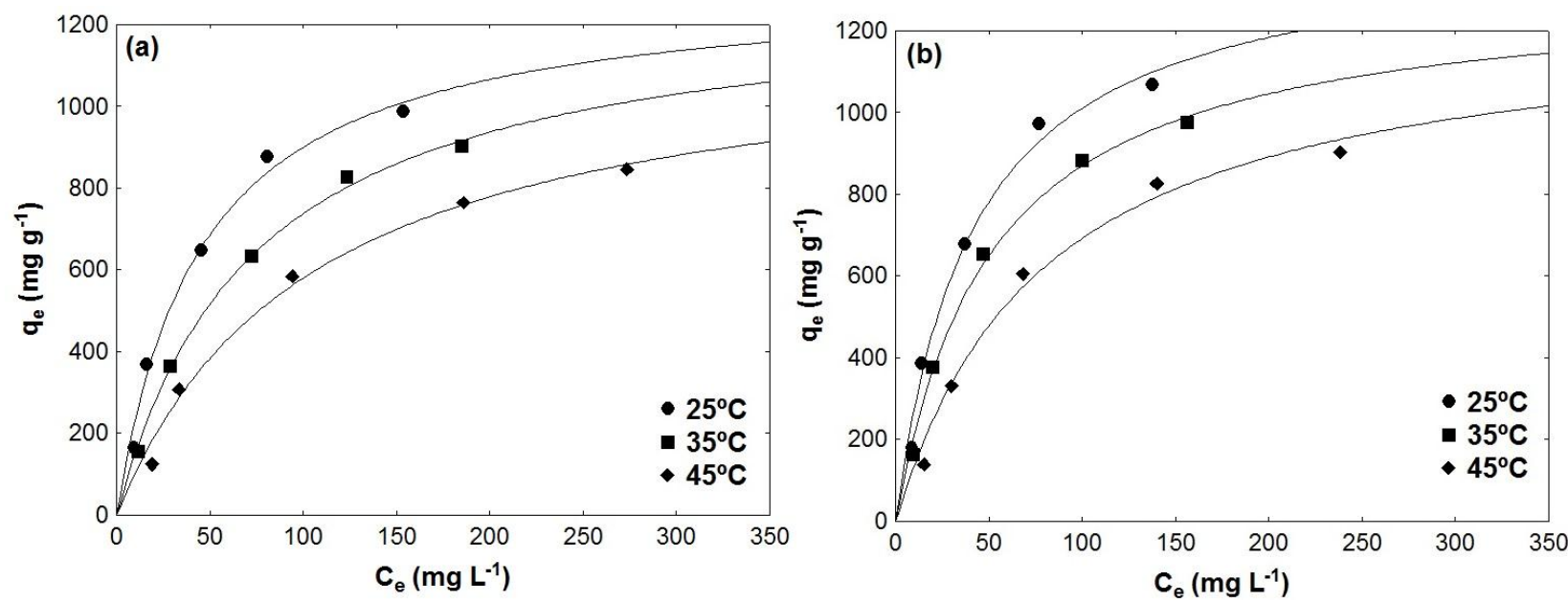

A partir da Figura 2, pode ser observado que para ambos os adsorventes, conforme ocorre o aumento da temperatura houve uma diminuição na capacidade de adsorção. Normalmente a operação de adsorção é um processo exotérmico, justificando este comportamento. Conforme ocorre o aumento da temperatura, a solubilidade dos corantes na solução tende a aumentar, assim dificultando a interação do corante com o adsorvente e, consequentemente, diminuindo a capacidade de adsorção (Crini e Badot, 2006). Esquerdo et al. (2014) observaram o mesmo comportamento em relação a temperatura, nas isotermas de adsorção de diferentes corantes alimentícios, utilizando uma esponja porosa à base de quitosana como adsorvente.

Na Figura 2, pode ser observado que o hidrogel com carvão ativado obteve uma capacidade de adsorção maior em relação ao outro hidrogel, isso pode ter ocorrido devido a maior disponibilidade de sítios ativos presente neste adsorvente.

A fim de representar as curvas de equilíbrio, os dados experimentais foram ajustados ao modelo de Langmuir e estes estão apresentados na Tabela 1. 
Tabela 1 -Parâmetros de equilíbrio para a adsorção do corante azul indigotina por hidrogéis de quitosana.

\begin{tabular}{|c|c|c|c|c|}
\hline \multirow{2}{*}{ Adsorventes } & \multirow{2}{*}{ Parâmetros } & \multicolumn{3}{|c|}{ Temperatura } \\
\hline & & $25^{\circ} \mathrm{C}$ & $35^{\circ} \mathrm{C}$ & $45^{\circ} \mathrm{C}$ \\
\hline \multirow[t]{4}{*}{ Hidrogel } & $\mathrm{q}_{\mathrm{m}, 1}\left(\mathrm{mg} \mathrm{g}^{-1}\right)$ & 1306,7 & 1284,9 & 1186,3 \\
\hline & $\mathrm{k}_{\mathrm{L}}\left(\mathrm{L} \mathrm{mg}^{-1}\right)$ & 0,0022 & 0,0013 & 0,0009 \\
\hline & $R^{2}$ & 0,995 & 0,995 & 0,997 \\
\hline & $\operatorname{EMR}(\%)$ & 3,7 & 1,9 & 5,3 \\
\hline \multirow[t]{4}{*}{ Hidrogel com carvão } & $\mathrm{q}_{\mathrm{m}, 1}\left(\mathrm{mg} \mathrm{g}^{-1}\right)$ & 1428,5 & 1311,9 & 1250,4 \\
\hline & $\mathrm{k}_{\mathrm{L}}\left(\mathrm{L} \mathrm{mg}^{-1}\right)$ & 0,0024 & 0,0019 & 0,0012 \\
\hline & $R^{2}$ & 0,998 & 0,997 & 0,992 \\
\hline & $\operatorname{EMR}(\%)$ & 4,3 & 3,6 & 4,1 \\
\hline
\end{tabular}

A partir da Tabela 1, mostra que os valores de $\mathrm{q}_{\mathrm{m}}$ foram aumentados em função da diminuição da temperatura, confirmando que a capacidade de adsorção foi favorecida em $25^{\circ} \mathrm{C}$. Os dados experimentais das isotermas de equilíbrio apresentaram um bom ajuste ao modelo de Langmuir $\left(R^{2}>0,98\right.$ e $\left.E M R<5,0 \%\right)$.

\section{CONCLUSÃO}

Neste trabalho, foi avaliado o potencial de diferentes hidrogéis liofilizados, com e sem a presença de carvão ativado, para a adsorção do corante azul brilhante. Os adsorventes apresentaram grau de intumescimento de $113 \%$ e $135 \%$ para os hidrogéis sem e com carvão respectivamente. A máxima capacidade de adsorção obtida para os adsorventes foram de 1306 e $1428 \mathrm{mg} \mathrm{g}^{-1}$ para os hidrogéis sem e com carvão, respectivamente, mostrando um excelente potencial desses adsorventes.

\section{NOMENCLATURA}

Símbolo

$\mathrm{C}_{0}$

$\mathrm{C}_{\mathrm{e}}$

$\mathrm{k}_{\mathrm{L}}$

$\mathrm{m}$

$\mathrm{q}_{\mathrm{e}}$

\section{Definição}

Concentrações inicial

Concentrações final na fase líquida

Constante de Langmuir

Massa de adsorvente

Capacidade de adsorção de equilíbrio
Unidade

$\left(\mathrm{mg} \mathrm{L}^{-1}\right)$

$\left(\mathrm{mg} \mathrm{L}^{-1}\right)$

$\left(\mathrm{L} \mathrm{mg}^{-1}\right)$

(g)

$\left(\mathrm{mg} \mathrm{g}^{-1}\right)$ 
Volume da solução

$M_{t}$ Massa do hidrogel hidratado no determinado tempo

$M_{0}$ Massa do hidrogel inicial

\section{REFERENCIAS BIBLIOGRÁFICAS}

ANVISA: Agência Nacional De Vigilância Sanitária. Decreto $n^{\circ}$ 55.871/65 de 26 de março de 1965. Portaria no 540/97, de 27 de outubro de 1997. Disponível em: http://www.anvisa.gov.br. 1997.

CRINI, G.; BADOT, P. M. Application of chitosan, a natural aminopolysaccharide, for dye removal from aqueous solutions by adsorption processes using batch studies: A review of recent literature. Prog. Polym. Sci., v. 33, p. 399-447, 2008.

CARONI, A. L. P. F.; DE LIMA, C. R. M.; PEREIRA, M. R.; FONSECA, J. L. C. The kinetics of adsorption of tetracycline on chitosan particles. J. Colloid Interface Sci., v. 340, p. 182-191, 2009.

DAllAGO, R. M.; SMANIOTTO, A.; OlIVEIRA, L. C. A. Resíduos sólidos de curtumes como adsorventes para a remoção de corantes em meio aquoso. Quim. Nova, v.28, p. 433-437, 2005.

DEMIRBAS, A. Agricultural based activated carbons for the removal of dyes from aqueous solutions: A review. J. Hazard. Materials., v. 167, p. 1-9, 2009.

DOTTO, G. L.; VIEIRA, M. L. G.; GONÇALVES, J. O.; PINTO, L. A. A. Remoção dos corantes azul brilhante, amarelo crepúsculo e amarelo tartrazina de soluções aquosas utilizando carvão ativado, terra ativada, terra diatomácea, quitina e quitosana: Estudos de equilíbrio e termodinâmica. Quím.Nova, v. 34, p. 1193-1199, 2011.

KOPRIVANAC, N.; KUSIC, H. Hazardous organic pollutants in colored wastewaters. New York: New Science Publishers, 2008.

MITTAL, A.; MITTAL, J.; KURUP, L. Utilization of hen feathers for the adsorption of indigo carmine from simulated effluents. J. Environ. Protect. Sci., v. 1, p. 92-100, 2007.

SHEN C.; SHEN Y.; WEN Y.; WANG H.; LIU W. Fast and highly efficient removal of dyes under alkaline conditions using magnetic chitosan-Fe(III) hydrogel. Water Res., v. 45, p. 5200-5210, 2011.

WAN NGAH, W. S.; TEONG, L. C.; HANAFIAH, M. A. K. M. Adsorption of dyes and heavy metal ions by chitosan composites: A review. Carbohydr Polymer., v. 83, p. 1446-1456, 2011.

ZHOU, P.; REGENSTEIN, J. M. Comparison of water gel desserts from fish skin and pork gelatins using instrumental measurements. J. Food Sci., v.72, p.196-201, 2007. 